\title{
ФОРМИРОВАНИЕ СТРАТЕГИИ МАСШТАБИРОВАНИЯ ВНЕДРЕНИЯ ТЕХНОЛОГИЙ ЧЕТВЕРТОЙ ПРОМЫШЛЕННОЙ РЕВОЛЮЦИИ
}

\author{
(c) 2021 Кузнецова Мария Олеговна \\ старший преподаватель Департамента менеджмента и инноваций \\ Факультета «Высшая школа управления» \\ Финансовый университет при Правительстве Российской Федерации, Россия, Москва \\ E-mail: MOKuznetsova@fa.ru
}

В статье предложена стратегия масштабирования внедрения технологий четвертой промышленной революции. Проведен обзор российской и зарубежной литературы по проблемам цифровой трансформации компании и внедрения технологий четвертой промышленной революции. Был предложен интегрированный подход к формированию стратегии масштабирования внедрения технологий четвертой промышленной революции, который позволяет эффективно реализовать цифровую трансформацию в компании.

Ключевые слова: четвертая промышленная революция, Индустрия 4.0, цифровая трансформация, стратегия.

\section{Введение}

Технологии Четвертой промышленной революции способны оказывать значительное влияние на особенности ведения бизнеса, организации производства и формирование ресурсной базы для обеспечения производства. Технологии Индустрии 4.0 направлены на повышение темпов и масштаба изменений бизнеса [1, с. 43-50].

Индустрия 4.0 оказывает значительное влияние на компании различных отраслей, что обуславливается появлением новых технологий, которые формируют абсолютно новые способы удовлетворения потребностей клиентов и вносят существенные изменения в процессы создания цепочки ценностей компании [1, с. 43-50].

С переходом к четвертой промышленной революции следует выделить основные тенденции для различных отраслей промышленного производства. К ним относятся: [1, с. 43-50]:

- изменение ожиданий потребителей;

- повышение уровня качества продуктов, посредством технологий, которые позволяют повысить эффективность использования активов;

- формирование и создание новых форм различных партнерств;

- трансформация операционных моделей бизнеса в цифровые бизнес-модели.

Изменение ожиданий потребителей

- ожидания клиентов направлены не только на качество продукта, но и на такие аспекты, как бренд, клиентское обслуживание, упаковка и т.д.
- изменение принципов сегментации рынка и выделение целевой группы с учетом критериев цифровизации;

- клиентоориентированность;

- внедрение цифровых технологий направлено на повышение качества производимых товаров и услуг, а также на повышение эффективности и объемов данных, которые предоставляются клиентам [1, с. 43-50].

Повышение уровня качества продуктов, посредством технологий, которые позволяют повысить эффективность использования активов

- совершенствование аналитических инструментов, что позволяет проводить непрерывный мониторинг изделия, продукции и своевременно устранять возникающие дефекты;

- возможность для создания новых бизнесмоделей;

- осуществление прогнозирования функциональности продукции [1, с. 43-50].

Формирование и создание новых форм различных партнерств (коллаборативные инновации)

Цифровые технологии Четвертой промышленной революции направлены на совместное использование компаниями ресурсов посредством совместно реализуемых инноваций, что позволяет создавать дополнительную ценность для всех заинтересованных сторон процесса. Подобные коллаборации могут быть направлены на создание новых бизнес-моделей [1, с. 43-50].

Трансформация операционных моделей бизнеса в цифровые бизнес-модели 
- обусловлено необходимостью пересмотра собственных операционных моделей;

- стратегии создания цифровых платформ компаний во многом направлено на обеспечение эффективности производства и повышения клиентоориентированности;

- совершенствование существующих бизнес-моделей за счет данных (информации), направленных на создание новых источников доходов, которые основаны на более широком доступе к информации о клиентах;

- увеличение объемов инвестирования в системы информационной безопасности;

- изменение цифровых моделей обуславливает необходимость изменений в корпоративной культуре современных компаний;

- актуальность сетевых организационных структур компаний.

Представленные следствия Индустрии 4.0 должны учитываться при формировании стратегий масштабирования внедрения цифровой технологии в современные компании [1, с. 43-50].

Стратегии масштабирования внедрения технологий четвертой промышленной революции: обзор исследований

В рамках исследования был проведен обзор российской и зарубежной литературы, который позволил рассмотреть основные современные практики в области формирования стратегий масштабирования внедрения технологий четвертой промышленной революции.

Компанией Team International [3] предлагается поэтапное руководство, направленное на реализацию стратегии масштабирования внедрения технологий четвертой промышленной революции. Эксперты отмечают важность обеспечения гибкости и адаптируемости стратегии цифровой трансформации к корпоративным изменениям. В рамках данного фреймворка предложено 7 этапов реализации стратегии масштабирования внедрения технологий Индустрии 4.0 (таблица 1) [3].

Таблица 1. Этапы реализации стратегии масштабирования внедрения технологий Четвертой промышленной революции по методике компании Team International

\begin{tabular}{|c|c|}
\hline Этапы реализации стратегии & Особенности \\
\hline $\begin{array}{l}\text { 1. Разработка дорожной карты } \\
\text { цифровой трансформации }\end{array}$ & $\begin{array}{l}\text { Карта цифровой трансформации должна включать: } \\
\text { - план трансформации корпоративной инфраструктуры; } \\
\text { - оценку компетенций сотрудников для внедрения цифровой трансфор- } \\
\text { мации в компании; } \\
\text { - формирование списка корпоративных технологий для обновления; } \\
\text { - формирование дерева целей цифровой трансформации с определением } \\
\text { основных приоритетов; } \\
\text { - назначение ответственных исполнителей реализации каждого этапа } \\
\text { цифровой трансформации }\end{array}$ \\
\hline $\begin{array}{l}\text { 2. Подбор сотрудников, облада- } \\
\text { ющих необходимым уровнем } \\
\text { компетенций в области цифро- } \\
\text { вой трансформации }\end{array}$ & Подбор специалистов в сфере IT-технологий \\
\hline $\begin{array}{l}\text { 3. Применение данных бизнес- } \\
\text { аналитики }\end{array}$ & $\begin{array}{l}\text { Качественная бизнес-аналитика позволит повысить эффективность меро- } \\
\text { приятий по реализации цифровой трансформации. Качественная бизнес- } \\
\text { аналитика основывается на четырех аспектах: технологии и системы; } \\
\text { данные и аналитика; таланты и корпоративная культура; операционная } \\
\text { модель и партнерские отношения }\end{array}$ \\
\hline 4. Планирование бюджета & $\begin{array}{l}\text { Необходимо обеспечение эффективного планирования бюджета, т.к. циф- } \\
\text { ровая трансформация требует значительных финансовых ресурсов }\end{array}$ \\
\hline 5. Подбор IT-инструментов & $\begin{array}{l}\text { От качества подобранных IT-инструментов зависит эффективность осу- } \\
\text { ществления цифровой трансформации компании, которая включает в себя } \\
\text { комплексные процессы автоматизации и роботизации рабочих процессов } \\
\text { в компании }\end{array}$ \\
\hline $\begin{array}{l}\text { 6. Формирование команды для } \\
\text { целей реализации цифровой } \\
\text { трансформации }\end{array}$ & $\begin{array}{l}\text { Команда должна быть гибкой и способной быстро адаптироваться к из- } \\
\text { менениям внешней среды. Важно определить лидеров, которые способны } \\
\text { продвигать идеи цифровой трансформации в компании }\end{array}$ \\
\hline $\begin{array}{l}\text { 7. Осуществление непрерывно- } \\
\text { го мониторинга эффективности } \\
\text { реализации цифровой транс- } \\
\text { формации компании }\end{array}$ & $\begin{array}{l}\text { В рамках данного этапа можно проанализировать насколько были достиг- } \\
\text { нуты цели цифровой трансформации компании. Вместе с тем, данный этап } \\
\text { позволяет выделить «узкие места» процесса цифровой трансформации, } \\
\text { что является важным аспектом при корректировке процесса цифровой } \\
\text { трансформации }\end{array}$ \\
\hline
\end{tabular}

Источник: составлено автором по материалам исследования [3]. 
Таким образом, концепция компании Теат International, направленная на формирование стратегии масштабирования внедрения технологий четвертой промышленной революции основывается на 7 последовательных этапах, которые могут корректироваться по мере необходимости.

Другой подход к реализации стратегии масштабирования внедрения технологий четвертой промышленной революции предложен консалтинговой компанией BCG, которая выделяет шесть факторов, направленных на успешную реализацию данной стратегии (таблица 2) [2].

Для успешной реализации стратегии масштабирования цифровой трансформации компаниям необходимо фокусироваться на технологиях, которые будут широко распространяться и масштабироваться. Это позволит повысить эффективность реализации стратегии масштабирования внедрения технологий четвертой промышленной революции в современных компаниях.
Консалтинговой компанией McKinsey [7] предлагается выделять пять групп факторов, которые направлены на эффективную разработку и реализацию стратегии масштабирования внедрения технологий четвертой промышленной революции. К ним относятся [7]:

- лидеры, обладающими компетенциями в области цифровых технологий;

- создание возможностей для сотрудников непрерывно совершенствоваться;

- создание прав и возможностей для сотрудников работать в новых бизнес-моделях;

- цифровое обновление инструментов и подходов к управлению бизнес-процессами компании;

- обеспечение коммуникаций сотрудников с помощью традиционных и цифровых методов.

Подробнее каждый аспект формирования стратегии масштабирования внедрения технологий четвертой промышленной революции представлен в таблице 3 [7].

Представленные шаги реализации страте-

Таблица 2. Факторы успешной реализации стратегии масштабирования внедрения технологий четвертой промышленной революции согласно подходу консалтинговой компании BCG

\begin{tabular}{|c|c|}
\hline Факторы & Характеристики \\
\hline $\begin{array}{l}\text { 1. Комплексная стратегия с опре- } \\
\text { делением четких целей цифровой } \\
\text { трансформации }\end{array}$ & $\begin{array}{l}\text { Важно формировать интегрированную стратегию цифровой транс- } \\
\text { формации, которая включает видение, стратегические цели с четко } \\
\text { определенными количественными результатами, что должно быть на- } \\
\text { правлено на установление взаимосвязей цифровых технологий, общей } \\
\text { бизнес-стратегии и устойчивого конкурентного преимущества. Страте- } \\
\text { гия должна преобразовываться в конкретные действия, включенные в } \\
\text { дорожную карту бизнеса }\end{array}$ \\
\hline $\begin{array}{l}\text { 2. Приверженность высшего и } \\
\text { среднего менеджмента масштаб- } \\
\text { ным изменениям цифровой транс- } \\
\text { формации компании }\end{array}$ & $\begin{array}{l}\text { Управление цифровой трансформацией компании должно осущест- } \\
\text { вляться на всех горизонтальных и вертикальных уровнях управления } \\
\text { компанией }\end{array}$ \\
\hline $\begin{array}{l}3 \text { Управление талантами в компа- } \\
\text { нии в целях осуществления цифро- } \\
\text { вой трансформации компании }\end{array}$ & $\begin{array}{l}\text { Для успешной реализации цифровой трансформации в компании } \\
\text { важно особое внимание уделять привлечению талантливых кадров на } \\
\text { руководящие должности. Для успешной реализации цифровой транс- } \\
\text { формации в компании важны следующие качества сотрудников такие, } \\
\text { как настойчивость, прагматизм, устойчивость, критическое мышление, } \\
\text { креативность, эмоциональный интеллект и способность к обучению. }\end{array}$ \\
\hline $\begin{array}{l}\text { 4. Образ мышления гибкого управ- } \\
\text { ления }\end{array}$ & $\begin{array}{l}\text { Важно учитывать два аспекта: наличие гибкого мышления и внедре- } \\
\text { ние гибкого поведения в организацию. Гибкость сотрудников является } \\
\text { одним из важнейших аспектов при внедрении технологий четвертой } \\
\text { промышленной революции. Руководство компании должно обеспечи- } \\
\text { вать высокую сопротивляемость изменениям со стороны сотрудников } \\
\text { компании для эффективной реализации процессов цифровой транс-- } \\
\text { формации }\end{array}$ \\
\hline $\begin{array}{l}\text { 5. Непрерывный мониторинг } \\
\text { достигнутых результатов процесса } \\
\text { цифровой трансформации }\end{array}$ & $\begin{array}{l}\text { Непрерывный мониторинг позволит выявлять препятствия и пробле- } \\
\text { мы, с которыми сталкивается компания на пути цифровой трансформа- } \\
\text { ции. От того насколько качественно будут выявлены барьеры, препят- } \\
\text { ствующие цифровой трансформации будет зависеть эффективность } \\
\text { разработанных мероприятий по преодолению сложившихся барьеров }\end{array}$ \\
\hline $\begin{array}{l}\text { 6. Подбор эффективных техноло- } \\
\text { гий и цифровых платформ данных }\end{array}$ & $\begin{array}{l}\text { Направлено на эффективное управление процессами цифровой } \\
\text { трансформации в компании и оценку эффективности реализованных } \\
\text { мероприятий }\end{array}$ \\
\hline
\end{tabular}

Источник: составлено по материалам исследования [2]. 
гии масштабирования внедрения технологий четвертой промышленной революции позволят повысить эффективность проведения цифровой трансформации компаний.
Компанией aiim было выделено шесть важнейших факторов, которые необходимо для успешной стратегии масштабирования технологий цифровой трансформации (таблица 4) [4].

Таблица 3. Факторы успешной разработки и реализации стратегии масштабирования внедрения технологий четвертой промышленной революции согласно подходу консалтинговой компании МсКіnsey

\begin{tabular}{|c|c|}
\hline Факторы & Особенности \\
\hline $\begin{array}{l}\text { Лидеры, обладающими компетенци- } \\
\text { ями в области цифровых технологий }\end{array}$ & $\begin{array}{l}\text { Наличие лидеров, обладающих компетенциями в области цифровых } \\
\text { технологий, позволит ускорить процесс цифровой трансформации и } \\
\text { повысить его эффективность }\end{array}$ \\
\hline $\begin{array}{l}\text { Создание возможностей для сотруд- } \\
\text { ников непрерывно совершенство- } \\
\text { ваться }\end{array}$ & $\begin{array}{l}\text { Важно фокусировать внимание на развитии навыков и компетенций } \\
\text { персонала, на повышении их уровня квалификации в области циф- } \\
\text { ровых технологий. Это позволит повысить мотивацию персонала в } \\
\text { части осуществления цифровой трансформации компании }\end{array}$ \\
\hline $\begin{array}{l}\text { Создание прав и возможностей } \\
\text { для сотрудников работать в новых } \\
\text { бизнес-моделях }\end{array}$ & $\begin{array}{l}\text { Повышение уровня принятия процессов цифровой трансформации } \\
\text { сотрудниками компании. Снижение уровня сопротивления измене- } \\
\text { ниям в части цифровой трансформации }\end{array}$ \\
\hline $\begin{array}{l}\text { Цифровое обновление инструментов } \\
\text { и подходов к управлению бизнес- } \\
\text { процессами компании }\end{array}$ & $\begin{array}{l}\text { - использование цифровых инструментов для обеспечения доступ- } \\
\text { ности информации, что более чем вдвое увеличивает вероятность } \\
\text { успешной трансформации; } \\
\text { - внедрение цифровых технологий самообслуживания для использо- } \\
\text { вания сотрудниками, деловыми партнерами или обеими группами; } \\
\text { - организации, изменяющие свои стандартные операционные про- } \\
\text { цедуры для включения новых технологий }\end{array}$ \\
\hline $\begin{array}{l}\text { Обеспечение коммуникаций сотруд- } \\
\text { ников с помощью традиционных и } \\
\text { цифровых методов }\end{array}$ & $\begin{array}{l}\text { В целях обеспечения эффективной коммуникации возможно при- } \\
\text { менять как традиционные методы, так и современные цифровые } \\
\text { методы, которые также направлены на повышение эффективно- } \\
\text { сти цифровой трансформации в компании. Согласно проведенным } \\
\text { исследованиям консалтинговой компанией MсКіnsey использование } \\
\text { удаленных и цифровых коммуникаций для передачи видения транс- } \\
\text { формации является более эффективным, чем личные или традицион- } \\
\text { ные каналы }\end{array}$ \\
\hline
\end{tabular}

Источник: составлено по материалам исследования [7].

Таблица 4. Факторы успешной реализации стратегии масштабирования технологий четвертой промышленной революции согласно подходу компании aiim

\begin{tabular}{|l|l|}
\hline \multicolumn{1}{|c|}{ Фактор } & \multicolumn{1}{c|}{ Особенности } \\
\hline $\begin{array}{l}\text { 1. Формирование бюджета проекта по } \\
\text { цифровой трансформации компании }\end{array}$ & $\begin{array}{l}\text { Формирование статей расходов и доходов в рамках цифровой транс- } \\
\text { формации компании }\end{array}$ \\
\hline 2. Обучение сотрудников компании & $\begin{array}{l}\text { Наличие сотрудников, которые хотят и могут обучаться технологи- } \\
\text { ям Четвертой промышленной революции, что позволит обеспечить } \\
\text { рост компании за счет конкурентных преимуществ, обусловленных } \\
\text { цифровыми технологиями }\end{array}$ \\
\hline $\begin{array}{l}\text { 3. Выбор технологий } \\
\text { трансформации }\end{array}$ & $\begin{array}{l}\text { Необходимо фокусироваться на ключевых технологиях и не пере- } \\
\text { гружать сотрудников большим количеством серьезных изменений } \\
\text { одновременно }\end{array}$ \\
\hline $\begin{array}{l}\text { 5. Подготовка компании к цифровой } \\
\text { трансформации }\end{array}$ & $\begin{array}{l}\text { Развернутый план цифровой трансформации предполагает учет } \\
\text { всех необходимых ресурсов для внедрения новых технологий Инду- } \\
\text { стрии 4.0 и обеспечения цифровой трансформации }\end{array}$ \\
$\begin{array}{l}\text { Идентификация сильных и слабых сторон, угроз и возможностей } \\
\text { для осуществления цифровой трансформации. Важно оценить } \\
\text { готовность сотрудников и компаниь к изменениям, связанным с } \\
\text { осуществлением цифровой трансформации }\end{array}$ \\
\hline 6. Роль управления изменениями & $\begin{array}{l}\text { Важно обеспечить вовлеченность сотрудников в процессы цифровой } \\
\text { трансформации, управлять изменениями и снижать сопротивление } \\
\text { сотрудников процессам цифровой трансформации }\end{array}$ \\
\hline
\end{tabular}

Источник: составлено автором по материалам исследования [4]. 
Цифровая трансформация является совокупностью сложнейших комплексных процессов, которые осуществляются в каждой компании индивидуально. Нет унифицированного подхода к реализации процесса цифровой трансформации и внедрения технологий Индустрии 4.0. Компании в процессе цифровой трансформации используют определенные ресурсы, объемы финансирования, привлечение и обучение сотрудников исходя из специфики отрасли, сферы деятельности, масштаба производства и т.д.

Издание The Economic Times приводит в своей статье 10 шагов по автоматизации масштабирования цифровой трансформации [5], [6]:

1. Формирование видения автоматизации. Направлено на изменение мышления в компании. Является важным этапом при формировании дорожной карты цифровой трансформации компании.

2. Разработка экономического обоснования проекта цифровой трансформации. В рамках данного этапа важно привлечь основных стейкхолдеров компании к инвестированию в реализацию цифровой трансформации компании.

3. Поддержка цифровой трансформации высшим руководством. Важно заручиться поддержкой топ-менеджмента компании в вопросах осуществления цифровой трансформации компании.

4. Вовлечение стейкхолдеров компании в процессы цифровой трансформации. Для успешного осуществления цифровой трансформации компании важно заручиться поддержкой ключевых заинтересованных сторон, включая руководителей функциональных подразделений / отделов, владельцев процессов, группы кибербезопасности и т.д. Необходимо определить роли и ответственность каждого стейкхолдера процесса цифровой трансформации компании.

5. Вовлечение сотрудников в осуществление процессов цифровой трансформации. Кадровая стратегия должна рассматриваться во взаимосвязи со стратегией масштабирования.

6. Осуществление инвестирования в развитие персонала. Данный аспект направлен на возможность непрерывного обучения персонала, на повышение его уровня квалификации, проведение сертификации и т.д., что поможет повысить мотивацию сотрудников, а также обеспечит вовлеченность в процессы цифровой трансформации.
7. Выстраивание приоритетов. Необходимо выстроить приоритеты в процессах реализации стратегии цифровой трансформации компании, что позволит ускорить реализацию цифровой трансформации.

8. Формирование центра передового опыта в компании, что позволит консолидировать множество проектов по осуществлению цифровой трансформации вокруг данного центра.

9. Формирование модели управления, которая предполагает необходимость согласования процессов цифровой трансформации с ИТ-командой, системой риск-менеджмента и внутреннего аудита. Вместе с тем, важно обеспечить согласование модели управления с ключевыми стейкхолдерами цифровой трансформации.

10. Поддержание операционной модели автоматизации. В рамках данного этапа необходимо обеспечить межорганизационную модель сотрудничества в процессах реализации цифровой трансформации, т.е. выстроить партнерские отношения со стейкхолдерами цифровой трансформации компании.

Автоматизация компаний позволяет повысить качество работы организации и взаимодействия с клиентами.

\section{Результаты исследования и выводы}

На основе проведенного обзора российской и зарубежной литературы можно выделить два подхода к формированию стратегии масштабирования внедрения технологий Индустрии 4.0:

1. Подход управления талантами.

2. Подход управления изменениями и учет интересов ключевых стейкхолдеров.

Последователями подхода к управлению талантами являются Team Internet, консалтинговая компания BCG, McKinsey\&Company. Для данного подхода следует выделить следующие характерные особенности:

- подбор персонала с высоким уровнем компетенций в области управления процессами цифровой трансформации;

- формирование команды, которая сможет реализовать процессы цифровой трансформации в компании;

- управление талантами в компании для осуществления процессов цифровой трансформации и внедрения технологий четвертой промышленной революции;

- создание возможностей для развития персонала. 
K представителям подхода управления изменениями и учета интересов заинтересованных сторон являются компания aiim и издание The Economic Times. В рамках данного подхода выделяются следующие особенности:

- подготовка компании к цифровой трансформации;

- управление изменениями в компании;

- поддержка цифровой трансформации топ-менеджментом компании;

- вовлечение персонала в процессы цифровой трансформации;

- вовлечение стейкхолдеров в процессы цифровой трансформации компании.

Таким образом, для обеспечения эффективной цифровой трансформации в компании предлагается рассматривать интегрированный подход, который включает в себя управление талантами, управление изменениями и учет интересов стейкхолдеров компании, вовлеченных в цифровую трансформацию (рисунок 1).

В рамках интегрированного подхода к формированию стратегии масштабирования вне- дрения технологий четвертой промышленной революции предлагается несколько этапов, которые позволят эффективно реализовать цифровую трансформацию в компании:

1. Постановка целей цифровой трансформации, что является важным этапом при разработке дорожной карты цифровой трансформации компании.

2. Оценка сильных и слабых сторон, возможностей и угроз при осуществлении цифровой трансформации. Выявление барьеров проведения цифровой трансформации компании. В рамках данного этапа также важно определить мероприятия, которые позволят преодолеть барьеры и использовать возможности для осуществления цифровой трансформации.

3. Вовлечение стейкхолдеров компании в процессы цифровой трансформации. Организация должна заручиться поддержкой ключевых заинтересованных сторон, включая руководителей функциональных подразделений / отделов, владельцев процессов, группы кибербезопасности и т.д. Необходимо определить роли и

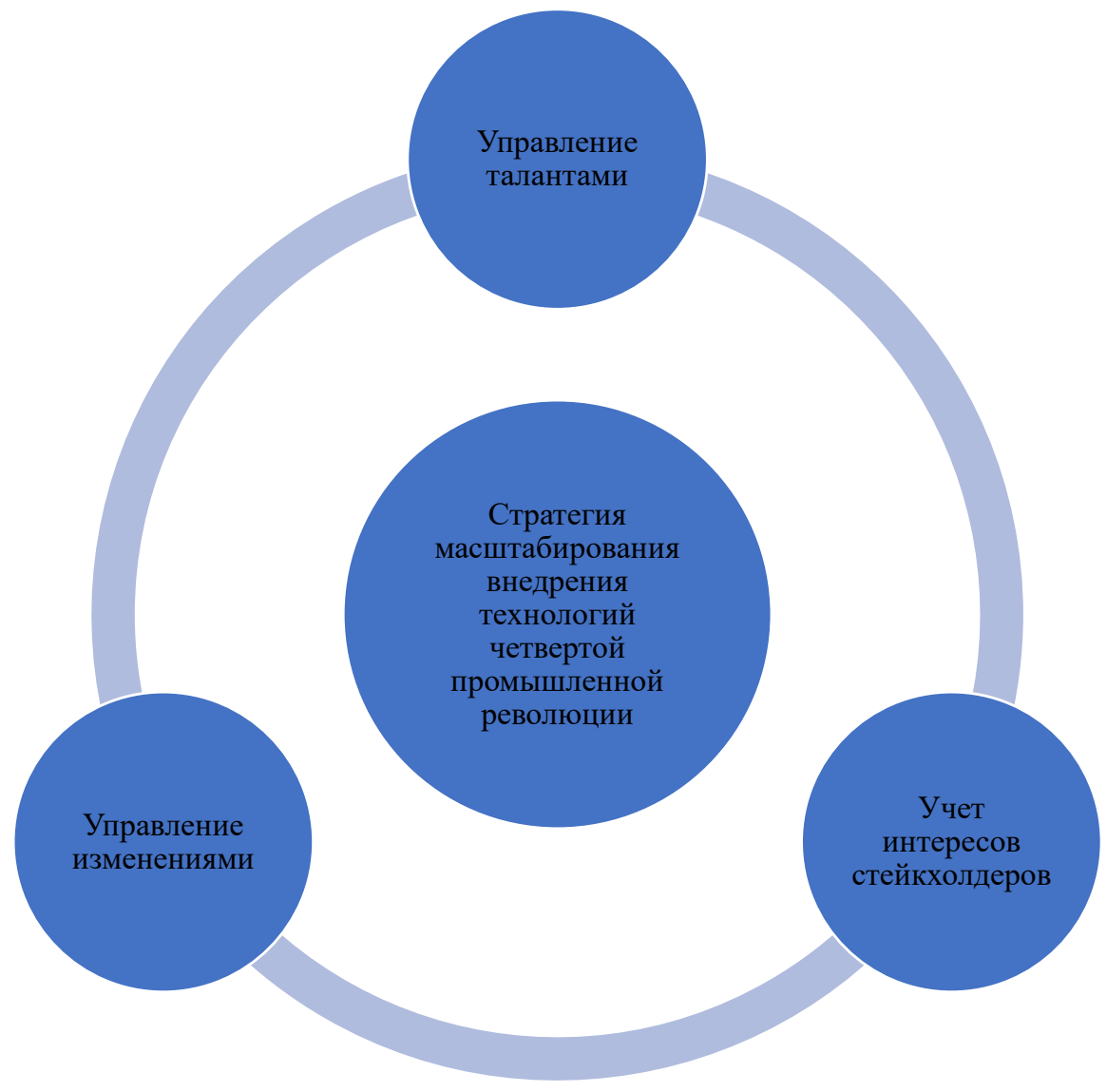

Составлено автором

Рисунок 1. Интегрированный подход к формированию стратегии масштабирования внедрения технологий четвертой промышленной революции 
ответственность каждого стейкхолдера процесса цифровой трансформации компании.

4. Инвестирование в развитие человеческого капитала компании. Важно обеспечить возможность непрерывного обучения сотрудников компании, повышать их квалификацию, проводить сертификацию и т.д. Это поможет повысить мотивацию сотрудников, а также обеспечит вовлеченность в процессы цифровой трансформации.

5. Управление изменениями и снижение уровня сопротивления внедряемым технологиям Индустрии 4.0. Вместе с тем, важно обеспечивать вовлеченность сотрудников в процессы цифровой трансформации компании, повышать их мотивацию при внедрении процессов цифровой трансформации.

6. Осуществление непрерывного мониторинга в достижении результатов цифровой трансформации. Непрерывный мониторинг позволит выявлять препятствия и проблемы, с которыми сталкивается компания на пути цифровой трансформации. От того насколько качественно будут выявлены барьеры, препятствующие цифровой трансформации будет зависеть эффективность разработанных мероприятий по преодолению сложившихся барьеров.

Предложенные этапы позволят осуществить эффективную цифровую трансформацию в компании посредством интегрированного подхода к управлению процессами цифровой трансформации, комплексного взгляда с позиции управления талантами, управления изменениями и учета интересов заинтересованных сторон компании, вовлеченных в цифровую трансформацию.

Статья подготовлена по результатам исследований, выполненных за счет бюджетных средств по государственному заданию Финуниверситета.

\section{Библиографический список}

1. Шваб, К. Четвертая промышленная революция / К.Шваб - «Эксмо», 2016 - (Top Business Awards). - 138 с.ISBN 978-5-699-90556-0.

2. Flipping the Odds of Digital Transformation Success / BCG // URL: https://www.bcg.com/ru-ru/publications/2020/ increasing-odds-of-success-in-digital-transformation.- (дата обращения 16.08.2021).

3. How to scale your digital business transformation / team international // URL: https://www.teaminternational. com/how-to-scale-your-digital-business-transformation/.- (дата обращения 16.08.2021).

4. Scaling Your Business for Digital Transformation - 6 Important Factors / aiim // URL: https://info.aiim.org/aiimblog/how-to-scale-your-business-for-digital-transformation.- (дата обращения 16.08.2021).

5. The 10 Step Roadmap to Scaling Automation Part1: Setting up success with stakeholder involvement / The Economic Times // URL: https://economictimes.indiatimes.com/tech/technology/the-10-step-roadmap-toscaling-automation-part1-setting-up-success-with-stakeholder-involvement/articleshow/81683070.cms. (дата обращения 16.08.2021).

6. The 10 Step Roadmap to Scaling Automation Part2: Accelerating digital transformation / The Economic Times // URL: https://economictimes.indiatimes.com/tech/technology/the-10-step-roadmap-to-scaling-automationpart2-accelerating-digital-transformation/articleshow/81932847.cms. - (дата обращения 16.08.2021).

7. Unlocking success in digital transformations / McKinsey\&Company // URL: https://www.mckinsey.com/businessfunctions/organization/our-insights/unlocking-success-in-digital-transformations. - - (дата $\quad$ обращения 16.08.2021). 